\title{
Migração interestadual e desigualdade racial: evidência do Estado de São Paulo
}

ELAINE MEIRE UILELA"

KARL MONSMA"

\section{Resumo}

$\mathrm{O}$ artigo avalia as consequências da presença de migrantes de outros estados brasileiros para a renda de negros e brancos paulistas. A literatura sociológica internacional inclui amplo debate sobre as consequências da imigração para os trabalhadores nativos, mas pouca discussão das consequências das migrações internas para os trabalhadores do local de destino dos migrantes. Usando os microdados do censo de 2010, estimamos modelos estatísticos hierárquicos para examinar o efeito contextual da proporção de migrantes em cada município do interior paulista sobre os salários de negros e brancos nativos. Os resultados mostram primeiro, que negros nativos do interior de São Paulo sofrem forte discriminação no mercado de trabalho relativo aos brancos nativos, que diminui seus salários em mais de dez per cento, em comparação com brancos com os mesmos níveis de escolarização e experiência nas mesmas categorias ocupacionais. A migração interestadual também se associa com aumentos salariais significativos para a população nativa, efeito que continua forte e altamente significante mesmo quando controlamos o PIB dos municípios. Este resultado é coerente com a literatura sobre as migrações internacionais, e mostra que a migração interna pode beneficiar trabalhadores nativos da mesma maneira que a imigração internacional. Os resultados também mostram que os benefícios da migração podem estar um pouco maiores para os brancos nativos que para os negros nativos, mas esse efeito é fraco e não significante. Estes resultados se referem às

\footnotetext{
* Universidade Federal de Minas Gerais (Brasil).

${ }^{* *}$ Universidade Federal do Rio Grande do Sul (Brasil).
} 
tendências gerais e podem esconder efeitos maiores nos salários dos negros nativos em ocupações ou indústrias específicas. É importante complementar esta pesquisa com o exame das mesmas tendências separadamente dentro das categorias ocupacionais e ao longo do tempo.

Palavras-chave: Migração interna. Desigualdade racial. Trabalhadores migrantes. Estado de São Paulo.

\title{
Interstate migration and racial inequality: evidence from São Paulo state
}

\begin{abstract}
The article examines the consequences of the presence of migrants from other states for the income of blacks and whites in São Paulo state. Although there is extensive debate within international sociological literature on the consequences of immigration for native workers, little discussion exists as to the consequences of internal migration for workers native to the regions that receive internal migrants. Using micro data from the 2010 census, we built hierarchical statistical models to examine the contextual effect of the proportion of migrants in each municipality of São Paulo state on the wages of black and white native workers. The results show, first, that native blacks in São Paulo state experience severe discrimination in the labor market relative to native whites, which reduces their wages by more than ten per cent, relative to white workers with the same levels of education and experience in the same occupational categories. Interstate migration is also associated with significant wage increases for the native population, an effect that remains strong and highly significant even when we control the GDP of municipalities. This result is consistent with the literature on international migration, and shows that internal migration can benefit native workers in the same way as international immigration. The results also show that the benefits of migration could be slightly higher for native whites than for the native blacks, but this effect is weak and nonsignificant. These results concern general trends and could hide larger effects on the wages of native blacks in particular occupations or industries. This research should be complemented by investigation of the same tendencies separately within each occupational category and over time.
\end{abstract}

Keywords: Internal migration. Racial inequality. Migrants' work. São Paulo state. 


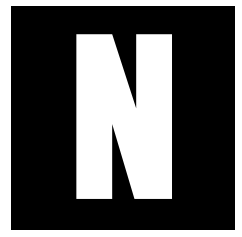

este artigo, avaliamos possíveis consequências das migrações interestaduais para a desigualdade racial no interior de São Paulo. A literatura sociológica internacional e nacional inclui amplo debate sobre as consequências das migrações internacionais para os trabalhadores nativos do país de destino, mas pouca discussão das consequências das migrações internas para os trabalhadores do local de destino dos migrantes. Uma das questões centrais no debate sobre as migrações internacionais é se a imigração prejudica ou beneficia os mais pobres e os integrantes de grupos prejudicados pelo racismo ou outras formas de discriminação; entretanto são raras as pesquisas sobre o efeito da migração interna sobre tais minorias no local de destino. Não conhecemos nenhum estudo empírico sobre esta questão no Brasil.

Para sanar tal lacuna, este artigo examina as relações entre a presença de migrantes, de qualquer identidade racial ou étnica, de outros estados brasileiros e a posição econômica dos negros e brancos paulistas, focalizando a renda daqueles com emprego. Seguindo a prática já estabelecida na literatura científica pertinente, definimos como "negros" aqueles que se identificam como "pretos" ou "pardos" (ver, por exemplo, Hasenbalg, 2005; Hasenbalg; Valle Silva, 2003; Aguiar, 2007). Vale destacar que não é possível, dentro dos limites deste artigo, abordarmos o debate sobre a racialização, ou o conjunto de processos sociais pelos quais alguns grupos étnicos categorizam outros como intrinsecamente diferentes e inferiores, e as consequências disso para as identidades daqueles assim categorizados (Jenkins, 1997; Miles, 1993). Em vez disso, examinamos algumas das consequências da racialização.

Entretanto, é importante notar que as categorias do censo constituem um esquema de classificação imperfeito para os propósitos deste artigo, em parte, porque se baseiam na autoidentificação e não na clas- 
sificação pelos outros que discriminam; em parte, porque as categorias censitárias predefinidas, branco, pardo e preto, não refletem com total fidelidade as categorias de cor que as pessoas acionam na vida cotidiana. Este artigo usa os dados imperfeitos do censo, porque são os únicos que permitem a pesquisa quantitativa sobre desigualdades raciais simultaneamente nos níveis individual e municipal.

Trabalhando com os microdados da amostra pública do censo de 2010, estimamos modelos estatísticos hierárquicos para examinar o efeito contextual da proporção de migrantes no município de residência dos paulistas sobre os salários de negros e brancos nativos. Estimamos um conjunto de modelos para a renda dos trabalhadores paulistas separadamente para homens e mulheres, com correção do viés de seleção ocasionado pelas diferenças na probabilidade de ter emprego. Para apresentar os resultados do estudo, estruturamos o texto em quatro seções, além desta introdução e das considerações finais. A primeira discute a literatura sobre as consequências da imigração para a situação de minorias no mercado de trabalho. Em seguida, trazemos uma sucinta discussão sobre os possíveis efeitos da imigração interna para os nativos no estado de São Paulo. Logo após, descrevemos os dados e a metodologia utilizada para mensurar esses efeitos. A quarta seção é onde apresentamos os resultados da análise dos dados, considerando as teorias e a hipótese central proposta.

\section{O debate sobre as consequências} da imigração para as minorias

Existe um debate extenso na literatura internacional, sobretudo naquela dos Estados Unidos, sobre as consequências da imigração para a posição econômica das minorias estigmatizadas e discriminadas do país de acolhimento. Como boa parte da migração dos países pobres para os 
países ricos consiste em trabalhadores braçais relativamente pouco escolarizados, e a muitos integrantes das minorias locais também faltam qualificação escolar ou títulos profissionais - justamente em consequência da discriminação passada e presente - a imigração tende a colocar os imigrantes e as minorias nativas em competição no mercado de trabalho (Catanzarite 2003; Mason 2014). Além do efeito dessa competição em reprimir os salários de todos os trabalhadores menos qualificados pela atuação de forças do mercado, os imigrantes gozam de várias vantagens sobre os nativos, e especialmente sobre os grupos racializados, por motivos a serem explicados abaixo. Portanto, embora a imigração em muitos casos beneficie as elites, a classe média e a economia em geral - por exemplo, estimulando o comércio e o mercado imobiliário, e permitindo a continuação de atividades produtivas que de outra maneira teriam sido deslocadas para outros países - ela tende a prejudicar os trabalhadores mais pobres e os menos qualificados do país de acolhimento, sobretudo as minorias (Catanzarite, 2003; Cherry, 2003; Johannsson; Shulman, 2003; Mason, 2014). No caso dos Estados Unidos, as pesquisas geralmente se concentram nas consequências da imigração para a população negra, embora algumas pesquisas também focalizem os efeitos para os latinos (descendentes de latino-americanos) nascidos nos EUA ou para os imigrantes que chegaram em levas anteriores (Jong; Madamba, 2001; Cherry 2003; Hall; Farkas, 2008; Roth, 2012).

Os imigrantes podem obter vantagens sobre os nativos no mercado de trabalho por vários motivos. Um dos mais importantes é a natureza seletiva da migração. Existe evidência da seletividade das migrações em geral, não somente das migrações internacionais. Aqueles que deixam sua terra de origem tendem a ser mais motivados, mais ambiciosos, mais persistentes e mais dispostos a enfrentar trabalho árduo tanto em relação àqueles, com a mesma origem social e nível educacional, que ficam, como em relação aos trabalhadores com as mesmas características sociais da terra de desti- 
no dos migrantes (Chiswick, 1999; Ferreira; Santos Júnior; Menezes-Filho, 2010). A imigração exige a busca por informações sobre oportunidades e a disposição para enfrentar empecilhos burocráticos, para aprender uma nova língua e novos costumes, para suportar maus tratos da polícia e a discriminação de empregadores, para sofrer o isolamento social e, sobretudo, para trabalhar muito. Os imigrantes também tendem a pensar sua estadia na nova terra como temporária e, geralmente, pretendem poupar dinheiro e depois voltar ao lugar de origem em situação melhor. Em função dessa orientação para o futuro, estão dispostos a aceitar sacrifícios e trabalhar longas horas. As diferenças no grau de motivação e assiduidade no trabalho com relação à população nativa do lugar de destino, provavelmente são superiores quando os salários neste local são notavelmente maiores do que aqueles na terra de origem. Além do mais, os migrantes também tendem a ser relativamente jovens e saudáveis, características que ajudam no mercado para empregos manuais (Piore, 1979).

Empregadores, muitas vezes, preferem os imigrantes, porque os consideram trabalhadores "melhores" do que os da população local, sobretudo aqueles dos grupos racializados e estigmatizados. Os trabaIhadores locais precisam enfrentar a competição, não de uma amostra representativa dos trabalhadores do local de origem dos migrantes, mas da parcela que reúne as características pessoais que geralmente agradam aos empregadores e contribuem para o sucesso. A natureza seletiva da imigração fica evidente nas pesquisas que comparam imigrantes negros caribenhos nos EUA com a população negra nativa do país, e os que comparam imigrantes latino-americanos com os latinos nascidos no país, em ambos os casos encontrando taxas de emprego maiores entre os imigrantes (Cherry, 2003, pp. 166-7).

Outra vantagem dos migrantes, frequentemente notada na literatura, é a presença de redes sociais densas que lhes ajudam a se colocar no mercado de trabalho. As redes mais densas e extensas do que aquelas dos 
nativos resultam, em parte, do processo migratório, geralmente organizado por meio de redes sociais. Um grande número de pesquisas mostra que as pessoas geralmente migram para destinos onde já têm conhecidos, especialmente parentes (por exemplo, Tilly, 1990; Portes; Bach, 1985; Briggs 2003). Como afirma Charles Tilly (1990), é a rede social que migra, não o indivíduo. A migração de redes leva à concentração de imigrantes de certas origens em regiões metropolitanas específicas, o que aumenta a densidade das redes de imigrantes e sua utilidade para os recém-chegados em busca de emprego (Briggs 2003). O fato de serem estrangeiros, muitas vezes isolados das redes sociais dos nativos, também tende a fortalecer as redes internas das comunidades de imigrantes e a tendência de se concentrarem em certas ocupações. Quando essa concentração atinge certo nível, é conveniente para os empregadores contratar novos empregados por indicação de seus empregados imigrantes (Matloff, 1996; Schwartzman, 2008, p. 148). Essa tendência é mais acentuada ainda quando os imigrantes falam outra língua, porque trabalhadores nativos geralmente não conseguem se comunicar com eles (Cherry, 2003). Finalmente, quando uma elite imigrante se concentra em certo ramo de negócios, normalmente dá prioridade à contratação de outros da mesma origem. O favorecimento de compatriotas por empresários imigrantes efetivamente exclui os negros de uma parte significativa dos empregos não qualificados em várias cidades dos Estados Unidos (Briggs, 2003). Como consequência desses fenômenos de contratação por meio de redes, grupos específicos de imigrantes podem rapidamente dominar certas ocupações ou tipos de negócios, quase impossibilitando a atuação de nativos nessas áreas (Bonacich, 1973).

Empregadores também podem preferir imigrantes sobre minorias nativas por motivos racistas. Por exemplo, podem ter internalizado vários estereótipos negativos de negros, ou dos negros nativos, e simplesmente não gostar deles, preferindo contratar imigrantes de qualquer origem 
ou cor, inclusive negros, a contratarem os negros nativos. Muitas vezes, empregadores usam o racismo dos outros como desculpa para não contratar negros ou integrantes de outros grupos racializados, alegando que os fregueses não querem ser servidos por pessoas do grupo estigmatizado, ou ainda que os outros trabalhadores não aceitem a presença de tais minorias. A imigração facilita a discriminação racial, porque fornece uma alternativa à contratação dos integrantes de minorias racializadas (Johannsson; Shulman 2003). Os imigrantes mesmos também podem rapidamente internalizar as atitudes racistas predominantes na sociedade de acolhimento, levando empregadores imigrantes a discriminarem os negros ou outros grupos racializados, e produzindo hostilidade aos negros entre os trabalhadores imigrantes, o que desincentiva a participação de negros em ocupações dominadas por imigrantes (Cherry, 2003; Monsma, 2006, 2014). Historicamente, a hostilidade de trabalhadores imigrantes contra negros aumentou mais ainda nos tempos e lugares onde empregadores usaram negros como fura-greves (Bonacich, 1972; Collins, 1997).

A presença de grande número de imigrantes internacionais em certas regiões pode desestimular a migração de minorias nacionais para essas regiões, se estas sabem que os imigrantes são preferidos no mercado de trabalho e os únicos empregos disponíveis a eles são pouco desejáveis. No caso dos Estados Unidos, há evidências históricas de que a "grande migração" dos negros do Sul para o Norte industrial se atrasou em várias décadas em função da imigração em massa de europeus para o Norte. Grandes números de negros só começaram a se mudar para o Norte com a queda da imigração, durante a primeira guerra mundial. Essa migração continuou depois da guerra com as novas restrições à imigração, e aumentou ainda mais durante a segunda guerra, com a forte demanda por mão-de-obra na indústria do Norte, o recrutamento de muitos trabalhadores para as forças armadas e a ausência da imigração de europeus (Briggs, 
2003; Collins, 1997). No Brasil, é provável que a grande imigração de europeus ao estado de São Paulo, no final do século XIX e início do XX, tenha atrasado em algumas décadas a migração em massa de nordestinos para São Paulo. Mais recentemente, é possível que a migração de nordestinos para as regiões mais prósperas de São Paulo esteja inibindo a migração de negros paulistas das regiões pobres do estado - especialmente o Sul - para essas mesmas regiões.

Vale destacar que muitos empregadores também preferem contratar imigrantes, porque eles podem ser explorados mais facilmente do que os trabalhadores nativos. Os migrantes de países pobres para países ricos aceitam salários mais baixos e condições de trabalho piores que os nativos tolerariam, pois, mesmo assim, os salários são bem maiores do que aqueles na terra de origem. Além do mais, muitos migrantes internacionais, especialmente os "ilegais", sem a documentação regularizada, não têm direitos trabalhistas. Mesmo aqueles com autorização oficial para trabaIhar, muitas vezes, não têm os mesmos direitos dos trabalhadores nativos, e podem relutar em reclamar de abusos, com medo de serem expulsos do país ou terem seus vistos cancelados. Nos casos em que o visto está vinculado à continuidade do contrato de trabalho, os imigrantes ficam particularmente vulneráveis à retaliação dos empregadores, se reclamarem. Essas desvantagens dos imigrantes traduzem-se em vantagens para os empregadores que, muitas vezes, preferem imigrantes aos nativos de qualquer cor. Em algumas indústrias, nos Estados Unidos, existe evidência da substituição de trabalhadores negros nativos por imigrantes, depois da organização de sindicatos de trabalhadores e uma escalada de conflitos entre os trabalhadores e a direção das empresas (Schwartzman, 2008).

Várias pesquisas estatísticas nos EUA, sobre as relações entre a imigração e os salários dos negros nativos, mostram um efeito negativo, mas relativamente pequeno, da imigração sobre a renda dos negros (Ma- 
son, 2014). Entretanto, quando se considera somente a imigração de pessoas com baixo nível educacional, os efeitos são maiores. Também são maiores em certos setores específicos do mercado de trabalho em que os imigrantes se concentram, e para os negros pouco escolarizados, que competem de maneira mais direta com os imigrantes (Catanzarite, 2003; Johannsson; Shulman 2003). Portanto, o efeito geral relativamente pequeno esconde prejuízos mais fortes para negros pouco qualificados, em certas ocupações específicas e provavelmente nas regiões com maior concentração de imigrantes.

Estudos históricos mostram a substituição de negros por imigrantes ao longo do tempo em ocupações específicas. Schwartzman (2008), por exemplo, apresenta evidências da substituição de trabalhadoras negras por imigrantes masculinos nos frigoríficos de frango no Sul dos Estados Unidos, ao longo das décadas de 1980 e 1990. Uma pesquisa realizada por uma agência do governo dos EUA encontrou evidências de que os empregadores de Los Angeles haviam sistematicamente demitido os faxineiros negros e os substituído por imigrantes, que aceitavam salários menores (Matloff, 1996, p. 64). Portanto, além de reprimir os salários em certas ocupações, a imigração pode levar ao deslocamento de trabaIhadores nativos para outras ocupações muitas vezes menos desejáveis, ou para o desemprego. Ainda outras pesquisas mostram um aumento da criminalidade de negros nas cidades onde a competição de imigrantes no mercado de trabalho braçal aumentou as taxas de desemprego de negros, provavelmente porque muitos são deslocados da economia formal para a economia criminosa, o que pode reforçar ainda mais os estereótipos negativos dos negros entre os brancos nativos (Harris; Feldmeyer, 2012; Mason, 2014; Shihadeh; Barranco 2010). 
Os possíveis prejuízos da migração interna para a população negra paulista

Algumas das especificidades de imigrantes mencionadas acima não estão presentes no caso de migrantes internos, que geralmente não enfrentam problemas de documentação e de permissão oficial para trabalhar e, por isso, são menos vulneráveis a abusos que imigrantes internacionais. Na maioria das vezes, também falam a mesma língua dos trabalhadores no lugar de destino. Entretanto, várias das outras características de imigrantes mencionadas acima também se evidenciam no caso de migrantes internos, e podem resultar em deslocamento ocupacional ou represamento dos salários dos trabalhadores nativos da região de destino dos migrantes, especialmente dos trabalhadores menos qualificados e dos integrantes de minorias estigmatizadas. A seletividade da migração, a tendência de pensá-la como temporária, as redes sociais mais densas, a tendência de predominar em certas ocupações e grandes diferenças salariais entre locais de origem e destino podem todos ocorrer com relação à migração entre regiões do mesmo país (Ferreira; Santos Junior; Menezes-Filho, 2010). Tal como no caso da migração internacional, os empregadores podem ter preconceitos racistas contra as minorias locais, preferindo contratar quaisquer outros quando disponíveis. Vale lembrar que há também os casos em que os empregadores buscam trabalhadores qualificados em outros estados para evitar os custos do treinamento da população local.

Não conhecemos pesquisas que avaliam as consequências da migração interna para a posição econômica de minorias nativas nos locais de destino dos migrantes. Isso é uma questão importante, porque os mesmos processos migratórios que servem para amenizar diferenças regionais de renda podem exacerbar as desigualdades sociais e raciais nas regiões que recebem muitos migrantes. O caso do estado de São Paulo 
é muito pertinente a esta questão, porque atrai grande número de migrantes relativamente pouco escolarizados, principalmente do Nordeste do país, os quais chegam a um estado com maioria branca e uma minoria significativa de negros, cuja escolarização, na média, é relativamente baixa e que sofrem o racismo e várias formas de discriminação no mercado de trabalho (Soares, 2000).

Os dados do censo de 2010 para o interior de São Paulo usados aqui mostram que, entre os migrantes de outros estados, $52 \%$ dos homens e $43 \%$ das mulheres não terminaram o ensino fundamental. Entre os negros paulistas, as percentagens dos que não terminaram o ensino fundamental são $41 \%$ para os homens e $34 \%$ para as mulheres, ao passo que as percentagens correspondentes entre os brancos paulistas são 29\% e 21\%. No outro extremo da escala educacional, entre paulistas brancos, $15 \%$ dos homens e $24 \%$ das mulheres completaram o ensino superior, ao passo que as percentagens entre paulistas negros e migrantes são muito menores: entre paulistas negros, $4 \%$ dos homens e $8 \%$ das mulheres; entre migrantes, $5 \%$ dos homens e $9 \%$ das mulheres. Ou seja, tanto para homens como para mulheres, a percentagem de negros paulistas que terminou o ensino fundamental é intermediária à dos paulistas brancos e a dos migrantes, e a percentagem de negros paulistas que terminou o ensino superior é parecida à dos migrantes, e muito abaixo da percentagem correspondente para brancos paulistas. Esses dados são consistentes com nossa suposição de que, no mercado de trabalho, os migrantes competem com os paulistas negros de maneira mais direta do que com os paulistas brancos.

Boa parte dos migrantes pouco qualificados encontra trabalho em setores econômicos específicos, como a agricultura, a construção civil ou o serviço doméstico, os quais exigem pouca escolarização, e onde competem com os paulistas relativamente pouco escolarizados, especialmente os negros. Na nossa amostra, $46 \%$ dos homens migrantes se empregam 
nas ocupações elementares ou como operários, artesãos ou outras ocupações braçais qualificadas. Nessas mesmas ocupações, concentram-se 44\% dos homens negros paulistas, ao passo que somente $31 \%$ dos homens brancos paulistas trabalham nelas. Entre as mulheres, 37\% das migrantes e 34\% das paulistas negras trabalham nas ocupações elementares, provavelmente concentrando-se especialmente no serviço doméstico. Entre as paulistas brancas, por outro lado, a percentagem nessa categoria de emprego cai para 19\%. No topo da distribuição ocupacional, 14\% dos homens brancos paulistas e $20 \%$ das mulheres brancas paulistas trabaIham como diretores, gerentes, profissionais da ciência ou intelectuais. Por outro lado, as percentagens correspondentes são 7\% para homens migrantes, 9\% para mulheres migrantes, 5\% para homens negros paulistas e $8 \%$ para mulheres negras paulistas. De maneira geral, o perfil ocupacional dos migrantes interestaduais é semelhante ao dos negros paulistas e destoa daquele dos brancos paulistas, o que novamente sugere maior grau de competição de migrantes com os negros nativos do que com os brancos nativos. A presença de migrantes dispostos a competir com negros pelos mesmos empregos pode reduzir os salários destes de duas maneiras: pelo mecanismo econômico do aumento da oferta de mão-de-obra relativa à demanda, e pela discriminação racial que se viabiliza pela disponibilidade de trabalhadores migrantes não negros.

A presença dos migrantes varia bastante entre as distintas regiões do estado de São Paulo, o que motiva a estimação dos efeitos contextuais, nos modelos estatísticos, da proporção imigrante em cada município sobre os rendimentos dos indivíduos. A partir da discussão teórica exposta acima, a nossa hipótese central é que a presença de maior proporção de migrantes interestaduais está associada com melhorias na situação econômica dos brancos nativos, mas pode prejudicar os negros, ou beneficiá-los menos. Em outras palavras, conjecturamos que, mesmo se a migração 
beneficiar os trabalhadores nativos de maneira geral, a competição mais direta dos negros nativos com os migrantes de outros estados pode piorar a situação relativa do negro no mercado de trabalho. Considerando tal hipótese, apresentamos a seguir os dados, os modelos analíticos e, logo após, os resultados da investigação. Aqui focalizamos a renda percebida por homens e mulheres no emprego principal, e estimamos modelos estatísticos hierárquicos pela influência da presença de migrantes e da cor/raça do indivíduo. Como é comum na pesquisa quantitativa com dados gerados por observação, examinamos as associações de variáveis independentes (de teste ${ }^{1}$ e de controle ${ }^{2}$ ) com a dependente (a que queremos explicar). É importante salientar que, baseados na nossa leitura da literatura internacional, nossa hipótese é coerente com os resultados de diversos estudos realizados em outros contextos, principalmente nos Estados Unidos. Isto é, identificamos acima processos plausíveis de competição no mercado de trabalho e de discriminação racial que fundamentam nossa hipótese de que, no interior do estado de São Paulo, um acréscimo na proporção de imigrantes interestaduais pode aumentar o grau de desigualdade racial entre os nativos (pardos ou pretos e brancos) do estado que recebe os migrantes. Abaixo avaliamos se os dados do estado de São Paulo (exceto Região Metropolitana) do censo de 2010 validam ou não tal hipótese.

\section{Os dados e os modelos analíticos}

Utilizamos dados do censo demográfico de 2010, do Instituto Brasileiro de Geografia e Estatística (Ibge, 2012). Nesta pesquisa tratamos indivíduos nascidos em São Paulo como paulistas e os trabalhadores nascidos em outros estados como migrantes. Destacamos que, além de nor-

\footnotetext{
${ }^{1}$ Variável que queremos usar para testar a hipótese: que explica a variável dependente.

${ }^{2}$ Variáveis que explicam a variável dependente mas que não se referem à hipótese a ser testada.
} 
destinos, há correntes migratórias fortes de outros estados, especialmente de Minas Gerais e Paraná, para São Paulo. Por isso, elegemos avaliar os efeitos contextuais da migração em geral e não somente a de nordestinos. Com o intuito de verificar se os negros nativos residentes no interior de São Paulo, em municípios com um percentual maior de migrantes interestaduais, estariam em pior situação (devido à competição com os "estrangeiros") do que aqueles residentes em municípios com um número menor de imigrantes, usamos uma subamostra de: a) indivíduos nativos do estado de São Paulo $^{3}$, b) residentes nas cidades do interior do estado de São Paulo ${ }^{4}$, c) pessoas empregadas ${ }^{5}$ no mercado de trabalho e d) entre 18 a 65 anos $^{6}$ de idade. Considerando que os mercados de trabalho para homens e mulheres são parcialmente distintos, separamos a amostra em dois bancos de dados, um com informações sobre os homens e outro sobre as mulheres, para poder realizar análises separadas.

Antes de discutir os modelos estatísticos, apresentamos as variáveis que os constituem. O quadro 1 sintetiza as variáveis utilizadas nos modelos, com suas formas funcionais e descrições. Nele encontram-se as

\footnotetext{
${ }^{3}$ Pessoas que declararam ter nascido no estado de São Paulo. Todos os imigrantes interestaduais e internacionais foram retirados da amostra após o cálculo dos valores agregados por município referente aos dados dos imigrantes interestaduais.

${ }^{4}$ Não incluímos os municípios que fazem parte da Região Metropolitana de São Paulo porque as pessoas nessa região facilmente moram em um município e trabalham em outro, fazendo com que as características do município de moradia sejam menos pertinentes à situação do indivíduo no mercado de trabalho.

${ }^{5}$ Uma amostra de empregados e desempregados foi utilizada anteriormente para mensurar a propensão de o indivíduo estar ou não empregado a partir de um modelo logístico de regressão. Após essa mensuração, criou-se uma variável que estima a probabilidade de cada indivíduo estar empregado ou não, e ela foi incluída no modelo hierárquico baseado apenas na amostra de pessoas empregadas.

${ }^{6} \mathrm{~A}$ idade mínima de 18 anos foi definida porque, em geral, pessoas nessa faixa etária têm grande probabilidade de já terem concluído o ensino médio, estando mais propensas a estarem inseridas no mercado de trabalho; a idade máxima de 65 anos deve-se ao fato de ser esta a idade de aposentadoria dos homens no Brasil no ano de 2010.
} 
variáveis dependente e independentes (de teste e de controle), sendo essas últimas divididas em variáveis em nível individual (micro) e em nível estrutural (macro) ${ }^{7}$, já que, segundo a literatura, para identificação do impacto da cor/raça sobre a situação do indivíduo no mercado de trabalho, faz-se necessário levar em conta características individuais e contextuais (Van Tubergen et al., 2004). Destacamos que, para facilitar a leitura e a discussão do tema dessa pesquisa, são aprofundadas as discussões nesse texto apenas acerca das variáveis de interesse utilizadas nos modelos: "negro", no nível individual, "percentual de migrantes no município, centralizado na média do estado", no nível macro, e o termo interativo entre essas duas variáveis.

\footnotetext{
${ }^{7}$ As variáveis de nível estrutural são características dos municípios de destino dos migrantes. Para a construção da variável "percentual de migrantes interestaduais, centralizado na média" (Perc_imigrante_cen), foram calculadas as proporções de imigrantes para cada município de destino e em seguida subtraída de cada valor a média geral para todos os municípios do estado.
} 
Quadro 1. Descrição das variáveis usadas na estimação dos modelos hierárquicos.

\begin{tabular}{|l|l|l|l|}
\hline \multicolumn{2}{|c|}{ Variável } & \multicolumn{1}{|c|}{ Tipo } & \multicolumn{1}{c|}{ Descrição } \\
\hline LnSáveis dependentes
\end{tabular}

continua...

${ }^{1} \mathrm{~A}$ idade é usada aqui como proxy de experiência no mercado de trabalho. Para solucionar o problema de colinearidade entre idade e idade ao quadrado, foi realizada a centralização dessas variáveis pela média da amostra, que consiste na subtração da idade pelo valor de sua média na amostra analisada (sendo essa a idade centralizada). Após feito isso, multiplica-se essa variável centralizada por ela mesma, constituindo assim a variável idade centralizada ao quadrado. 
Continuação

\begin{tabular}{|c|c|c|}
\hline Variável & Tipo & Descrição \\
\hline Fatdef & Binária & $\begin{array}{l}1=\text { Possui deficiência } / \\
0=\text { Não possui deficiência }\end{array}$ \\
\hline \multicolumn{3}{|l|}{ Posição no domicílio } \\
\hline Cônjuge & Binária & $1=$ Cônjuge/ 0 = responsável \\
\hline Filho & Binária & $1=$ Filho $/ 0$ = responsável \\
\hline Outraposdom & Binária & $\begin{array}{l}1=\text { Outra posição no domicílio/ } 0= \\
\text { responsável }\end{array}$ \\
\hline \multicolumn{3}{|l|}{ Estado civil } \\
\hline Solteiro & Binária & 1 = Solteiro $/ 0$ = Casado/separado/viúvo \\
\hline \multicolumn{3}{|l|}{ Religião } \\
\hline Protestante & Binária & $1=$ Protestante $/ 0$ = Católico \\
\hline Semrelig & Binária & $1=$ Sem religião $/ 0=$ Católico \\
\hline Outrarelig & Binária & $1=$ Outra religião $/ 0=$ Católico \\
\hline \multicolumn{3}{|c|}{ Grandes grupos ocupacionais $^{2}$} \\
\hline Ggocup1 & Binária & $\begin{array}{l}1=\text { gerentes e diretores } / 0=\text { ocupações } \\
\text { elementares }\end{array}$ \\
\hline Ggocup2 & Binária & $\begin{array}{l}1=\text { profissionais da ciência e intelectuais/ } \\
0=\text { ocupações elementares }\end{array}$ \\
\hline Ggocup3 & Binária & $\begin{array}{l}1 \text { = técnicos e profissionais do ensino } \\
\text { médio/ } 0=\text { ocupações elementares }\end{array}$ \\
\hline Ggocup4 & & $\begin{array}{l}1=\text { trabalhadores de serviço administrati- } \\
\text { vo/0 = ocupações elementares }\end{array}$ \\
\hline
\end{tabular}

continua...

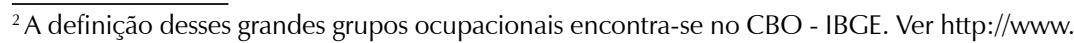
ibge.gov.br/home/estatistica/indicadores/sipd/oitavo_forum/COD.pdf 
Continuação

\begin{tabular}{|c|c|c|}
\hline Variável & Tipo & Descrição \\
\hline Ggocup5 & Binária & $\begin{array}{l}1=\text { trabalhadores de serviços, vendedores } \\
\text { dos comércios e mercados / } 0=\text { ocupa- } \\
\text { ções elementares }\end{array}$ \\
\hline Ggocup6 & Binária & $\begin{array}{l}1 \text { = trabalhadores da agropecuária, flores- } \\
\text { tais, da caça e da pesca/ } 0=\text { ocupações } \\
\text { elementares }\end{array}$ \\
\hline Ggocup 7 & Binária & $\begin{array}{l}1=\text { trabalhadores qualificados, operários, } \\
\text { artesãos da construção, das artes mecâ- } \\
\text { nicas e de outros ofícios / } 0=\text { ocupações } \\
\text { elementares }\end{array}$ \\
\hline Ggocup8 & Binária & $\begin{array}{l}1 \text { = operadores de instalações e má- } \\
\text { quinas e montadores } / \text { trabalhadores de } \\
\text { apoio administrativo } / 0=\text { ocupações ele- } \\
\text { mentares }\end{array}$ \\
\hline Ggocup10 & Binária & $\begin{array}{l}1=\text { membros das forças armadas, poli- } \\
\text { ciais e bombeiros militares } / 0=\text { ocupa- } \\
\text { ções elementares }\end{array}$ \\
\hline Ggocup11 & Binária & $\begin{array}{l}1=\text { ocupações mal definidas } / 0=\text { ocupa- } \\
\text { ções elementares }\end{array}$ \\
\hline Pro_empregado ${ }^{3}$ & Contínua & $\begin{array}{l}\text { Propensão a estar empregado- Valor pre- } \\
\text { dito de uma regressão logística binária (es- } \\
\text { tar empregado ou não). }\end{array}$ \\
\hline \multicolumn{3}{|c|}{ Nível estrutural (municípios) } \\
\hline \multicolumn{3}{|c|}{ Variáveis de teste no nível macro } \\
\hline Perc_mig_cen & Contínua & $\begin{array}{l}\text { Percentual de migrantes interestaduais no } \\
\text { município, centralizado na média }\end{array}$ \\
\hline Neg_Perc_mig_cen & Contínua & $\begin{array}{l}\text { Termo interativo entre as variáveis negro e } \\
\text { percentual de migrantes interestaduais no } \\
\text { município,centralizado na média. }\end{array}$ \\
\hline
\end{tabular}

continua...

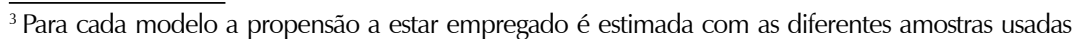
para os modelos: uma com todos (homens e mulheres); outra só de homens; e outra só de mulheres.
} 


\begin{tabular}{|l|l|l|}
\hline \multicolumn{3}{|c|}{ Variável de controle } \\
\hline Pib_percapita & Contínua & O PIB per capita do município em 2010. \\
\hline
\end{tabular}

Vale destacar que as variáveis independentes incluídas nos modelos são fundamentadas nas teorias de capital humano, de capital social, de capital cultural, do mercado segmentado e de significado social, como exposto pela literatura sobre estratificação social e/ou inserção do imigrante na sociedade hospedeira (por exemplo, Schultz 1973; Piore 1979; Tienda; Lii 1987; Bourdieu 1998a, 19998b; Borjas 1994, 2006; Portes 1995, 2000; Jong; Madamba 2001; Piché et al. 2002; Van Tubergen et al. 2004; Kesler; Hout 2010; Silva 1981; Hasenbalg; Valle Silva 2003; Ribeiro 2003, 2007, 2009; Hasenbalg 2005; Aguiar 2007; Ribeiro 2007; Santos 2009; Fernandes 2008; Monsma 2010; Vilela 2011; Vilela, Collares e Noronha 2015).

Destacamos que, em geral, os estudos sobre migração e mercado de trabalho no Brasil que utilizam amostras nacionais dão pouca ênfase às peculiaridades regionais do país (ver, por exemplo, Campante et al., 2004). Porém, em um estudo como este, em que o foco principal é a situação no mercado de trabalho de diferentes grupos de cor/raça, ou seja, o objetivo é detectar a existência ou não de discriminação ou outras formas de desigualdade racial no emprego, as diferenças entre municípios tornam-se relevantes para a seleção da metodologia utilizada. A literatura mostra que as características do município de residência e/ ou trabalho influenciam a condição socioeconômica do indivíduo, e tais características devem ser controladas na análise estatística (Van Tubergen et al. 2004; Vilela et al., 2015). 
As peculiaridades regionais influenciam as oportunidades disponíveis no mercado de trabalho e as reações dos empregadores às características dos trabalhadores, fazendo com que exista, entre grupos de trabalhadores de um mesmo município, certa interdependência ou similitude no que se refere à influência da cor/raça nos salários que é parcialmente diferenciada das influências que operam nos níveis estadual e/ou nacional. Em outras palavras, as relações entre salário e cor/ raça podem variar sistematicamente, dependendo das características do município, ficando essa variação intermunicipal perdida se levarmos em conta apenas o nível de agregação estadual. Além da perda de informação, há também o problema de que essa interdependência entre trabalhadores de um mesmo município viola a pressuposição de independência entre as observações, necessária para a validade das análises de regressão linear multivariada (Gujarati, 2006). Dessa forma, não levar em conta os agrupamentos municipais pode causar uma distorção nos coeficientes de regressão de modelos que procurem prever a relação entre salários e cor/raça. Não corrigir essa dependência entre trabalhadores do mesmo município também pode causar uma distorção (superestimação) no erro residual e, consequentemente, afetar os testes de significância das variáveis utilizadas nos modelos.

Sob essa perspectiva, o Modelo Hierárquico de Regressão ${ }^{8}$ mostra-se o mais adequado, visto que considera, na estimação dos parâmetros, a correlação dos erros (a influência de todas as variáveis pertinentes à renda não incluídas no modelo) para os indivíduos localizados em um mesmo município, permitindo um uso mais eficiente dos dados. Construímos, então, dois níveis de análises, sendo o primeiro correspondente às características individuais e o segundo composto por medidas agregadas referentes ao município de residência do indivíduo. A análise hierárquica

\footnotetext{
${ }^{8}$ Para mais informação sobre o modelo ver Goldstein 2003; Raudenbush; Bryk 2002.
} 
controla a heterogeneidade observada em nível contextual, ou agregado, permitindo ainda a partição da variabilidade da variável resposta em variação individual e variação em nível contextual, além da inclusão de controles específicos para este segundo nível.

Com intuito de corrigir um possível viés de seleção da amostra, foi realizado o teste sugerido por Heckman $(1979)^{9}$. O resultado do teste foi estatisticamente significante, indicando a existência de viés de seleção para o mercado de trabalho brasileiro, causado pelo fato de que os indivíduos com emprego não constituem uma amostra aleatória de toda a população com idades entre 18 e 65. Dessa forma, no modelo hierárquico é incluída uma variável preditora da propensão do indivíduo estar ocupado, estimada por meio de uma regressão logística, conforme indicado por Heckman ${ }^{10}$. A inclusão dessa variável controla a probabilidade de inserção do indivíduo no mercado de trabalho e, consequentemente, o viés de seleção da amostra. Quando realizado separadamente para as amostras de homens e de mulheres, o teste de Heckman também aponta a existência de viés de seleção para cada grupo. Foram calculadas separadamente as propensões de homens e de mulheres terem empregos, e essa variável foi incorporada nos modelos específicos para cada grupo de gênero.

Definimos os modelos hierárquicos finais pela seguinte equação principal:

\footnotetext{
${ }^{9} \mathrm{O}$ autor sugere a utilização de um modelo de regressão com duas equações simultâneas, uma linear e uma probit, para correção de casos possíveis de viés de seleção nas amostras. No caso desse estudo, o viés pode ocorrer se selecionarmos apenas os casos de indivíduos que trabaIham, excluindo os desocupados, porque variáveis não observadas, principalmente aquelas que influenciam decisões individuais de entrar ou sair do mercado de trabalho, podem estar correlacionadas tanto com a probabilidade de ter emprego como com o salário dos empregados, criando uma correlação entre os erros das variáveis probabilidade de ser empregado e salário, o que enviesa as estimativas das variáveis incluídas no modelo para salário.

${ }^{10}$ Isso porque o modelo hierárquico não aceita a inclusão do modelo Heckman automaticamente.
} 
Nível 1: individual

$\boldsymbol{L N S A L}=\beta 0+\beta 1^{*}(\mathrm{NEGRO})+\beta 2 *(E D U C 1)+\beta 3 *(E D U C 2)+$ $\beta 4^{*}\left(\right.$ EDUC3) $+\beta 5^{*}($ FATDEF $)+\beta 6^{*}($ IDADECEN $)+\beta 7^{*}($ IDADECEN2) $+\beta 8 *($ URBANO $)+\beta 9 *(S O L T E I R O)+\beta 10 *(C O N J U G E)+\beta 11 *(F I L H O)$ $+\beta 12 *($ OUTRAPOSDOM $)+\beta 13 *($ PROTEST $)+\beta 14 *($ OUTRAREL $)$ $+\beta 15^{*}($ SEMRELIG $)+\beta 16^{*}($ LNHORASTRAB $)+\beta 17^{*}($ GGRUPOS1) $+\beta 18 *($ GGRUPOS 2$)+\beta 19 *($ GGRUPOS3) $+\beta 20 *($ GGRUPOS4) + $\beta 21 *($ GGRUPOS5) $+\beta 22 *($ GGRUPOS6) $+\beta 23 *($ GGRUPOS7) + $\beta 24 *(G G R U P O S 8)+\beta 25 *$ (GGRUPOS10) $+\beta 26 *($ GGRUPOS11) + $\beta 27^{*}\left(P R O \_\right.$EMPREG $)+r$

Nível 2: estrutural $\beta_{0 j}=\gamma_{00}+\gamma_{01}{ }^{*}($ PERC_MIG_CEN $)+\gamma_{02}{ }^{*}\left(\right.$ NEG_PERC_MICCEN $\left._{j}\right)+$ $\gamma_{02}^{*}\left(\mathrm{PIB} \_\right.$PERCAPITA $)+u_{0 j}$

Realizamos a análise separadamente para homens e mulheres, porque a inserção no mercado de trabalho acontece de forma diferente entre os sexos e, principalmente, quando a questão em foco é a desigualdade racial, conforme já exposto em estudos anteriores, como, por exemplo, o de Soares (2000) e Aguiar (2007). Estimamos três modelos para cada sexo: 1) o primeiro controla apenas o PIB per capita em nível do município; 2) o segundo modelo introduz como segunda variável contextual o percentual de migrantes entre os trabalhadores homens ou mulheres em cada município; 3) o terceiro acrescenta o termo interativo entre percentual de migrante e a variável (com valores 1 e 0 ) que identifica os indivíduos negros.

O PIB per capita municipal está fortemente associado ao número de vagas disponíveis no mercado de emprego; portanto, incluí-la é uma maneira de controlar a capacidade de o município atrair migrantes. Assim 
podemos avaliar a influência da migração nos níveis salariais independente do grau de desenvolvimento do município. A inclusão da segunda variável contextual, percentagem de migrantes entre os trabalhadores de cada município, permite estimar o efeito nos salários dos trabalhadores nativos de morar em municípios com maior a menor proporção de migrantes. $\mathrm{O}$ termo interativo entre a percentagem migrante e negro permite avaliar se o efeito da percentagem migrante para os negros é diferente de seu efeito para os brancos. Ou seja, já sabemos que os negros em geral recebem salários menores que brancos, mesmo quando têm as mesmas qualificações educacionais, experiência de trabalho e ocupações, mas incluímos esta variável interativa para avaliar se a desvantagem dos negros nativos com relação aos brancos nativos é ainda maior nos contextos com muitos migrantes, porque os migrantes provavelmente competem de maneira mais direta com os negros que com os brancos.

Apresentamos a seguir os resultados, focando nos estimadores das seguintes variáveis: negro, percentual de migrantes no município e o termo interativo entre essas duas variáveis ${ }^{11}$. É importante esclarecer que estimamos modelos estatísticos da realidade, mas um modelo não é a realidade. Quando referimos ao "efeito" de uma ou outra variável independente abaixo estamos falando do efeito estimado pelo modelo, que presume certa estrutura de relações causais. Acreditamos que tais efeitos representam relações causais reais, mas os modelos não comprovam a causalidade, porque se baseiam na estrutura de associações entre as variáveis, em combinação com nossas suposições sobre quais variáveis são pertinentes e o ordenamento causal delas. Ao final da análise só podemos dizer se os resultados são coerentes com nossa hipótese inicial ou não, o que aumenta ou diminui nossa confiança nela.

\footnotetext{
${ }^{11}$ As estimativas para os modelos completos podem ser solicitadas aos autores.
} 
Análise dos resultados

O primeiro ponto a verificar é o quanto a variação salarial dos indivíduos é efeito das heterogeneidades entre os municípios, mesmo depois de levar em conta as características individuais pertinentes. O que identificamos é que $4 \%$ (no caso dos homens) e 3\% (no caso das mulheres) de tal variação é explicada por essa heterogeneidade intermunicipal. Esse efeito é estatisticamente significante, demonstrando assim a importância de utilizar o modelo hierárquico para análise do rendimento no mercado de trabalho.

Em seguida, averiguamos os efeitos das nossas variáveis de interesse, a partir dos modelos propostos. Para facilitar a interpretação, além de apresentar na tabela 1 o coeficiente estimado (beta) para o efeito de cada variável no logaritmo natural da renda, apresentamos também o valor do exponencial do coeficiente menos um, multiplicado por cem [100( $\left.\left.e^{b}-1\right)\right]$, onde b é o coeficiente beta de determinada variável], que é a estimativa da percentagem de aumento ou diminuição de salário decorrente de um aumento de uma unidade na variável independente. O coeficiente para a variável negro representa o efeito de ser negro, em vez de branco, no logaritmo do salário, depois de controlar as outras variáveis no modelo, ou seja, comparando negros e brancos com os mesmos valores das variáveis que tipicamente influenciam o nível de remuneração, como educação, categoria ocupacional e experiência. O valor correspondente à variável negro na coluna \% da tabela 1 é o percentual estimado de diminuição salarial devido ao fato de ser negro comparado a ser branco, depois de controlar as outras variáveis no modelo. A redução salarial estimada para negros nativos, quando comparados a brancos nativos, é 10,6\% e para negras é maior ainda, chegando a quase $12,1 \%$. Embora a diferença entre homens e mulheres nos efeitos de ser negro não seja grande, a desvantagem maior para as negras encontrada aqui corrobora os resultados de 
estudos anteriores, como os de Soares (2000) e de Campante, Crespo e Leite (2004), os quais demonstram que as mulheres negras se encontram em pior situação no mercado de trabalho se comparadas às mulheres brancas, homens brancos ou homens negros.

Tabela 1. Modelos de regressão multinível para os salários de homens e mulheres.

\begin{tabular}{|c|c|c|c|c|c|c|c|c|c|c|c|c|}
\hline \multirow[t]{2}{*}{ Variáveis } & \multicolumn{2}{|c|}{$\begin{array}{l}\text { Modelo1 (para } \\
\text { homens) }\end{array}$} & \multicolumn{2}{|c|}{$\begin{array}{l}\text { Modelo1 (para } \\
\text { mulheres) }\end{array}$} & \multicolumn{2}{|c|}{$\begin{array}{l}\text { Modelo2 (para } \\
\text { homens) }\end{array}$} & \multicolumn{2}{|c|}{$\begin{array}{l}\text { Modelo2 (para } \\
\text { mulheres) }\end{array}$} & \multicolumn{2}{|c|}{ Model03 (para homens) } & \multicolumn{2}{|c|}{$\begin{array}{l}\text { Modelo3 (para } \\
\text { mulheres) }\end{array}$} \\
\hline & Beta & $\%$ & Beta & $\%$ & Beta & $\%$ & Beta & $\%$ & Beta & \begin{tabular}{|l|}
$\%$ \\
\end{tabular} & Beta & $\%$ \\
\hline negro & $-0,1119^{* * *}$ & $-10,59$ & $-0,1288^{* * *}$ & $-12,08$ & $-0,112^{* * *}$ & $-10,61$ & $-0,129$ & $-12,11$ & $-0,1125^{* * *}$ & $-10,64$ & $-0,1286^{* * *}$ & $-12,07$ \\
\hline per_mig_cen & & & & & $0,0063^{* * *}$ & 0,64 & 0,0061 & 0,61 & $0,0065^{* * *}$ & 0,65 & $0,0062^{* * *}$ & 0,62 \\
\hline neg_per_mig_cn & & & & & & & & & $-0,0003398$ & $-0,033$ & $-0,0005011$ & $-0,05$ \\
\hline Número de observaçõe: & \multicolumn{2}{|c|}{506.801} & \multicolumn{2}{|c|}{363.335} & \multicolumn{2}{|c|}{506.801} & \multicolumn{2}{|c|}{363.335} & \multicolumn{2}{|c|}{506.801} & \multicolumn{2}{|c|}{363.335} \\
\hline
\end{tabular}

Para o cálculo do percentual é necessário tirar o exponencial do Beta, subtrair um e multiplicar por 100. ***significar que o estimador é estatisticamente significativo ao nível de $99 \%$.

A variável contextual percentagem de migrantes interestaduais entre os trabalhadores do município exerce um efeito positivo e altamente significante nos salários dos trabalhadores, tanto para homens quanto para mulheres, mesmo depois de controlar o PIB per capita do município. Entre os trabalhadores masculinos, cada aumento de um ponto percentual na presença de migrantes no município aumenta os salários em 0,64\%, o que não é pouco. Por exemplo, um aumento no percentual de migrantes de $10 \%$ para $15 \%$ seria associado com um aumento de 3,2\% na média salarial dos trabalhadores nativos. Entre as mulheres nativas o efeito da presença de mulheres migrantes é somente um pouco menor, sendo um aumento salarial de $0,61 \%$ para cada ponto percentual de aumento na presença de mulheres migrantes. Ao contrário de estereótipos populares sobre a competição de migrantes, que "roubam nossos empregos", estes resultados sugerem que a presença de migrantes contribui para aquecer a atividade econômica local e aumentar os salários da população nativa. 
Este resultado é coerente com vários estudos das consequências da imigração relatados na literatura internacional e citados acima.

O efeito da variável negro permanece quase inalterado quando incluímos a variável contextual percentagem de migrantes interestaduais. Isto é, a diferença salarial entre negros e brancos nativos no interior do estado de São Paulo não é parcialmente uma consequência da distribuição espacial dos migrantes nesse estado. Isso sugere que, embora o efeito estimado da percentagem de migrantes interestaduais no município seja estatisticamente significante e relativamente forte, esta variável não está correlacionada com a variação entre municípios na percentagem de negros na população nativa. Ou seja, os migrantes de outros estados não se concentram mais em municípios com maior ou menor número de negros nativos.

Entretanto, ainda é possível que a presença de números maiores de migrantes esteja associada com salários maiores para os trabalhadores de maneira geral, mas com salários menores para os menos qualificados, especialmente os negros, que geralmente são menos escolarizados e também estigmatizados, podendo ser preteridos por empregadores quando migrantes competem pelos mesmos cargos, o que forçaria os negros a aceitarem empregos menos desejáveis, com salários menores. A literatura sobre as consequências das migrações internacionais para os trabalhadores nativos identifica uma tendência para consequências diferenciadas, com os benefícios concentrados mais entre os trabalhadores mais qualificados e benefícios menores, ou até prejuízos, para os menos qualificados, especialmente os integrantes de grupos minoritários estigmatizados e discriminados. Ou seja, mesmo quando resulta em benefícios para a economia como um todo, a imigração pode estar associada com aumentos na desigualdade social e racial, ou até com a redução da renda das categorias de trabalhadores que já são as mais pobres. 
O terceiro modelo, que inclui um termo pela interação entre a variável negro e a percentagem de migrantes, testa essa possibilidade de efeitos diferenciados da migração. O coeficiente da interação é negativo para homens e também para mulheres, como esperado, mas em ambos os casos é diminuto e não significante. Ou seja, não podemos ter confiança de que essa interação realmente exista, e não resulte da variação aleatória decorrente de imprecisões na medição das variáveis ou de variáveis não incluídas no modelo que influenciam a renda, mas não se correlacionam com as variáveis independentes focalizadas aqui. Mesmo se fossem estatisticamente significantes, os efeitos estimados para as interações sugerem que a migração beneficia os negros somente um pouco menos que os brancos. A diferença é tão pequena que poderia ser desconsiderada, se essa diferença média se aplicasse a todos os negros e brancos. Um grande aumento na percentagem de migrantes, de $10 \%$ para $20 \%$, por exemplo, se associa com um aumento de somente meio per cento na diferença entre os salários médios de mulheres negras e brancas, uma diferença que é menor ainda entre os homens.

Também é importante apontar que estes modelos indicam que a migração beneficia tanto negros como brancos da população nativa, só que o beneficio para os trabalhadores brancos pode ser levemente maior, o que seria coerente com a literatura discutida acima. Pelo modelo estimado, um aumento de dez pontos percentuais na percentagem de migrantes resulta em um aumento de 6,5\% nos salários de homens brancos nativos e em $6,2 \%$ nos de negros nativos; o mesmo aumento na percentagem de migrantes se associa com um aumento de 6,2\% nos salários de mulheres brancas e de $5,7 \%$ nos salários de negras ${ }^{12}$. Mesmo quando estimamos o mesmo modelo sem os controles para categorias ocupacionais, para verificar a hipótese de que a competição de migrantes desloca negros para tipos menos desejáveis de empregos, os coeficientes para a interação entre negro e per- 
centagem de migrantes continuam pequenos e não significantes. Entretanto, essa pequena diferença racial no efeito da percentagem de migrantes pode esconder diferenças maiores em ocupações específicas.

\section{Conclusão}

Esta análise mostra, primeiro, que negros nativos do interior de São Paulo sofrem fortes desvantagens no mercado de trabalho relativo aos brancos nativos, que diminuem seus salários em mais de dez por cento, quando comparados com os salários de brancos com os mesmos níveis de escolarização e experiência que trabalham nas mesmas categorias ocupacionais. Esta desigualdade salarial é um pouco maior para as mulheres que para os homens. Esses resultados confirmam as conclusões de muitas pesquisas anteriores. A questão da discriminação racial aparentemente mais forte contra mulheres negras merece mais pesquisa. Essa diferença pode ter a ver com a ênfase dos empregadores na aparência física das pessoas em cargos que exigem contato com o público, tipicamente ocupados por mulheres, tais como recepcionistas e balconistas, em combinação com padrões culturais de beleza que valorizam características físicas típicas de europeias e desvalorizam características típicas de africanas.

A pesquisa relatada aqui também mostra que a migração interestadual se associa com aumentos salariais significativos para a população nativa dos municípios que recebem os migrantes. Este resultado é coerente com a literatura sobre as migrações internacionais, e mostra que

\footnotetext{
${ }^{12} \mathrm{O}$ efeito (em percentagem), para o salário de negros, de um aumento de um ponto percentual na percentagem migrante, é calculado por $100\left(\mathrm{e}^{(\mathrm{b} 1+\mathrm{b} 2)}-1\right)$, onde b1 é o coeficiente pelo efeito da percentagem de migrantes em modelo 3 e b2 é o coeficiente pelo interação entre a variável negro e percentagem de migrantes do mesmo modelo.
} 
a migração interna pode aquecer economias locais da mesma maneira que a imigração internacional. $\mathrm{O}$ aumento da demanda por bens e serviços decorrentes da migração produz mais empregos, especialmente em certos setores, como no comércio. Como os migrantes, muitas vezes, se concentram em certos tipos de empregos, por exemplo, empregos braçais rurais ou na construção civil, os outros empregos gerados pela presença dos migrantes podem ser ocupados desproporcionalmente por trabalhadores nativos. Pode ser esse aumento na oferta de tipos de empregos tipicamente ocupados por nativos, em combinação com o crescimento limitado do número de nativos, que eleva seus salários. A associação positiva entre a percentagem de imigrantes e os salários dos nativos, que continua forte mesmo quando se controla o PIB per capita dos municípios, também sugere que boa parte dos benefícios da migração fica no município de destino.

A presença dos migrantes também pode viabilizar atividades econômicas que de outra forma não existiriam, ou estariam presentes em escala menor, nos locais de recebimento. Na literatura sobre os Estados Unidos, alguns dos autores discutidos acima apontam que a imigração permite a continuação de indústrias que de outra forma seriam deslocados para outros países com salários menores. Tanto nos Estados Unidos como em São Paulo, os migrantes são essenciais para a agricultura e para a construção, permitindo construções e formas de agricultura que de outra maneira seriam inviáveis. Essas indústrias também fornecem empregos para os nativos, que tipicamente são empregos melhores que aqueles ocupados por migrantes. Se a presença de migrantes viabiliza mais projetos de construção, esses mesmos projetos também geram empregos para trabalhadores especializados, como supervisores, eletricistas e encanadores, que muitas vezes são nativos. Se, até recentemente ${ }^{13}$, um exército de migrantes era necessário para cortar a cana produzida nas fazendas de São Paulo, essa 
mesma indústria também gerava empregos para trabalhadores especializados nas usinas de álcool e no transporte dos produtos. Com o crescimento da demanda por trabalhadores especializados, esses trabalhadores passam a ganhar mais que seus congêneres em municípios com menos migrantes.

Esses benefícios para a população nativa produzidos pela presença de migrantes podem ser acompanhados por outras consequências indesejáveis, como aumentos dos custos das moradias ou prejuízos ambientais causados pelas indústrias viabilizadas pelos trabalhadores migrantes. Também é provável que uma parte do benefício aos nativos se deve à discriminação contra os migrantes na contratação para os empregos melhores, ou pelo menos o favorecimento de nativos inseridos nas redes sociais locais.

Os resultados também mostram que os benefícios da migração podem ser um pouco maiores para os brancos nativos que para os negros nativos, mas esse efeito é fraco e não significante. Esta interação é um pouco maior, embora ainda pequena, entre as mulheres, possivelmente em função da competição direta entre migrantes e negras nativas no mercado por faxineiras e empregadas domésticas, uma área em que trabalham muitas nordestinas e negras paulistas. Dessa forma, os resultados desta análise não validam nossa hipótese inicial de que elevação da proporção de migrantes no município se associa com maior desigualdade entre brancos e negros. Entretanto, esses resultados se referem às tendências gerais e podem esconder consequências maiores da competição entre migrantes e negros nativos em ocupações ou indústrias específicas. É importante complementar esta pesquisa com o exame das mesmas tendências separadamente dentro das categorias ocupacionais (ou setores de atividade). Para confirmar estes resultados, também é importante pesqui-

\footnotetext{
${ }^{13}$ Nos últimos anos muitos cortadores de cana foram substituídos por máquinas, em função de restrições ambientais às queimadas, necessários para a colheita manual.
} 
sar as mudanças salariais ao longo do tempo e sua relação com mudanças na presença de migrantes. Finalmente, não pesquisamos diferenças na probabilidade de desemprego aqui porque usamos dados de 2010, um ano com taxa de desemprego relativamente baixa. Uma pesquisa com dados de outro censo, realizado em um ano de desemprego alto, pode revelar efeitos da migração nas probabilidades de desemprego que sejam diferentes para brancos e negros nativos.

Elaine Meire Vilela é Doutora em Ciência Humanas (Sociologia e Ciência Política) pela Universidade Federal de Minas Gerais e Professora do Programa de Pós -Graduação em Sociologia da Universidade Federal de Minas Gerais. $\triangle$ emvilela@gmail.com

Karl Martin Monsma é PhD em Sociologia pela Universidade de Michigan e Professor do Programa de Pós-Graduação em Sociologia da Universidade Federal do Rio Grande do Sul. \karlmonsma@hotmail.com

\section{Referências}

1. AGUIAR, N. O. (Ed.). Desigualdades sociais, redes de sociabilidade e participação política. Belo Horizonte: UFMG, 2007.

2. BONACICH, E. A theory of ethnic antagonism: The split labor market. American Sociological Review, v. 37, 547-559, October 1972.

3. BONACICH, E. A theory of middleman minorities. American Sociological Review, v. 38, n. 5, 583-594, Oct. 1973

4. BOURDIEU, P. O capital social - notas provisórias. In: NOGUEIRA, M. A.; CATANI Afrânio (Orgs). Escritos de educação. Petrópolis: Vozes, 1998a, p. 65-9.

5. BOURDIEU, P. Os três estados do capital cultural. In: NOGUEIRA, M. A; CATANI, Afrânio (Orgs). Escritos de educação. Petrópolis: Vozes, 1998b p.71-9.

6. BORJAS, G.J. The economics of immigration. Journal of Economic Literature, v. 32 , n. 4, p. 1667-1717, 1994.

7. BORJAS, G.J. Wage trends among disadvantaged minorities. In: BLANK, R.M.; DANZIGER, S.H., et al (Ed.). Working and poor: how economic and policy are affecting low-wage workers. New York: Russell Sage Foundation, 2006. p.59-86. 
8. BRIGGS, V.M. Jr. The economic well-being of black Americans: the overarching influence of U.S. immigration policies. The Review of Black Political Economy, v. 31, n. 1-2, pp. 15-42, summer-fall 2003.

9. CAMPANTE, F.R.; CRESPO, A.; LEITE, P.G.P.G. Desigualdade salarial entre raças no mercado de trabalho urbano brasileiro: aspectos regionais. Revista Brasileira de Economia. v. 58, n.2 pp. 185-210, 2004.

10. CATANZARITE, L. Occupational context and wage competition of new immigrant Latinos with minorities and whites. The Review of Black Political Economy, v. 31, n. 1-2, pp.77-94, summer-fall 2003.

11. CHERRY, R. Immigration and race: What we think we know. The Review of Black Political Economy, v. 31, n. 1-2, pp. 157-184, summer-fall 2003.

12. CHISWICK, B.R. Are immigrants favorably self-selected? The American Economic Review, v. 89, n. 2, pp. 181-185, 1999.

13. COLLINS, W.J. When the tide turned: Immigration and the delay of the Great Black Migration. The Journal of Economic History, v. 57, n. 3, pp. 607-632, Sept. 1997.

14. FERNANDES, F. Aintegração do negro na sociedade de classes. 5 ed. São Paulo: Globo, 2008.

15. FERREIRA, P.C.; SANTOS JÚNIOR, E.R.; MENEZES-FILHO, N. Migração, seleção e diferenças regionais de renda no Brasil. Rio de Janeiro: FGV, 2010

16. GOLDSTEIN, H. Multilevel statistical models, 2.ed. London: E. Arnold; New York: Halsted Press, 2003.

17. GUJARATI, D.N. Econometria Básica. 4ạ edição. Rio de Janeiro: Elsevier, 2006.

18. HALL, M.; FARKAS, G. Does human capital raise earnings for immigrants in the low-skill labor market? Demography, 2008, 45 (3): 619-639.

19. HARRIS, C.T.; FELDMEYER, B. Latino immigration and white, black and Latino violent crime: a comparison of traditional and non-traditional immigrant destinations. Social Science Research, v. 42, n. 1, 202-216, Jan. 2013.

20. HASENBALG, C. Discriminação e desigualdades raciais no Brasil, 2 ed. Belo Horizonte e Rio de Janeiro: UFMG e IUPERJ, 2005.

21. HASENBALG, C.; VALLE SILVA, N. Origens e destinos - desigualdades sociais ao longo da vida. Rio de Janeiro: Topbooks, 2003

22. HECKMAN, J.J. Sample selection bias as a specification error. Econometrica, v. 47 , n. 1, 153-162, 1979. 
23. JACINTO, P.A. Diferenciais de salário por gênero na indústria avícola da Região Sul do Brasil: uma análise com microdados. RER, v. 43, n. 3, pp. 529-555, 2005.

24. JENKINS, R. Rethinking ethnicity: arguments and explorations. Londres: Sage, 1997.

25. JOHANNSSON, H.; SHULMAN, S. Immigration and the employment of African American workers. The Review of Black Political Economy, v. 31, n. 1-2, 95-110, 2003.

26. JONG, G.F.; MADAMBA, A.B. A double disadvantage? Minority group, immigrant status, and underemployment in the United States. Social Science Quarterly, v. 82, n. 1, 117-129, 2001.

27. KESLER, C.; HOUT, M. Entrepreneurship and immigrant wages in US labor markets: a multi-level approach. Social Science Research, v. 39, n. 2, p. 187-201, Mar 2010.

28. MASON, P.L. Immigration and African American wages and employment: Critically appraising the empirical evidence. The Review of Black Political Economy, v. 41, n. 3, 271-297, Sept. 2014.

29. MATLOFF, N. How immigration harms minorities. The Public Interest, n. 124, 61-72, summer 1996.

30. MILES, R. Racism after 'race relations'. Londres e Nova York: Routledge, 1993.

31. MONSMA, K. Symbolic conflicts, deadly consequences: fights between Italians and blacks in western São Paulo, 1888-1914. Journal of Social History, v. 39, n. 4, p. 1123-1152, summer 2006.

32. MONSMA, K. Vantagens de imigrantes desvantagens de negros : emprego, propriedade, estrutura familiar e alfabetização depois da abolição do oeste paulista. Dados - Revista de Ciências Sociais, v. 53, n. 3, p. 509- 543, 2010.

33. MONSMA, K. Relações entre imigrantes e negros no oeste paulista, 18881914. In: ABREU, M. et al.(Org.) Histórias do Pós-Abolição no Mundo Atlântico, Vol. 2, O mundo do trabalho: Experiências e lutas pela liberdade. Niterói: Editora da UFF, 2014.

34. PICHÉ, V. et al. Economic integration of new immigrants in the montreal labor market: A longitudinalapproach. Population, v. 57, n. 1, p. 57-82, 2002.

35. PIORE, M.J. Birds of passage: Migrant labor and industrial societies. Cambridge: Cambridge University Press, 1979. 
36. PORTES, A. The economic sociology of immigration : essays on networks, ethnicity, and entrepreneurship. New York: Russell Sage Foundation, 1995.

37. PORTES, A. Capital social: origens e aplicações na Sociologia contemporânea. Sociologia, problemas e práticas, n. 33, p. 133-158, 2000.

38. PORTES, A.; BACH, R.L. Latin journey: Cuban and Mexican immigrants in the United States. Berkeley: University of California Press, 1985.

39. PORTES, A.; MANNING, R.D. The Immigrant Enclave: theory and Empirical Examples. In: GRUSKY, D.B. (org.). Social stratification: class, race, and gender in sociological perspective, 3 ed. Boulder, CO: Westview Press, 2008, 516-528.

40. PORTES, A.; RUMBAUT, R.G. Legacies: the story of the immigrant second generation. Berkeley, Calif.; New York, NY: University of California Press; Russell Sage Foundation, 2001.

41. RAUDENBUSH, S.W.; BRYK, A.S. Hierarchical linear models: Applications and data analysis methods. Thousand Oaks, Sage Publications, 2002.

42. REYNERI, E.; FULLIN, G. Labour market penalties of new immigrants in new and old receiving West European countries. International Migration Journal, n. 593, p. 1-27, 2009.

43. RIBEIRO, C.A.C. Estrutura de classes, condições de vida e oportunidades de mobilidade social no Brasil. In: HASENBALG, C.; VALLE SILVA, N. (Eds.). Origens e destinos: desigualdades sociais ao longo da vida. Rio de Janeiro: Topbooks, 381-425, 2003.

44. RIBEIRO, C.A.C. Estrutura de classe e mobilidade social no Brasil. São Paulo: Edusc, 2007.

45. RIBEIRO, C.A.C. Desigualdade de oportunidades no Brasil. Belo Horizonte: Argvmentvm, 2009.

46. ROTH, W. Race migrations: latinos and the cultural transformation of race. Redwood, CA, Stanford University Press, 2012.

47. SANTOS, J.A.F. A interação estrutural entre a desigualdade de raça e degênero no Brasil. Revista Brasileira de Ciências Sociais, v. 24, n. 70, 37-60, 2009.

48. SHIHADEH, E.S.; BARRANCO, R.E. Latino employment and black violence: the unintended consequence of U.S. immigration policy. Social Forces, v. 88, n. 3, 1393-1420, March 2010.

49. SCHULTZ, T.W. O capital humano: investimentos em educação e pesquisa. Rio de Janeiro: Zahar, 1973.

50. SCHWARTZMAN, K.C. Lettuce, segmented labor markets, and the immigration discourse. Journal of Black Studies, v. 39, n. 1, 129-156, Sept. 2008. 
51. SILVA, N.V. Cor e o processo de realização sócio-econômica. Dados - Revista de Ciências Sociais, v. 24, n. 3,. 391-409, 1981.

52. SOARES, S.S.D. O perfil da discriminação no mercado de trabalho - homens negros, mulheres brancas e mulheres negras. IPEA - Texto para discussão 769, 2000.

53. TIENDA, M.; LII, D.T. Minority concentration and earnings inequality: blacks, hispanics, and asians compared. American Journal of Sociology, v. 93, n. 1, 141165, 1987.

54. TILLY, C. Transplanted networks. In: YANS-MCLAUGHLIN, V. (org.) Immigration reconsidered: history, sociology, and politics. Nova York, Oxford University Press, 1990.

55. TUBERGEN, F.; MAAS, I.; FLAP, H. The economic incorporation of immigrants in 18 western societies:origin, destination, and community effects. American Sociological Review, v. 69, n. 5, 704-727, 2004.

56. VILELA, E.M. Desigualdade e discriminação de imigrantes internacionais no mercado de trabalho brasileiro. Dados - Revista de Ciências Sociais, v. 54, n. 1, 89-129, 2011.

57. VILELA, E.M; COLLARES, A.C.M.; NORONHA, C.L.A. Migrações e trabalho no Brasil: fatores étnico-nacionais e raciais. Revista Brasileira de Ciências Sociais, v. 30, n. 87, 19-42, fev. 2015.

Recebido: 27/03/2015.

Aceite final: 02/06/2015 